\title{
2,2-Bis(phenylsulfonyl)ethyl sulfides as efficient precursors of sulfenic acids
}

\author{
Maria C. Aversa, ${ }^{\text {a }}$ Anna Barattucci, ${ }^{\text {a* Paola Bonaccorsi, }}$, \\ Patrick Rollin, and Arnaud Tatibouët ${ }^{b}$ \\ ${ }^{a}$ Dipartimento di Chimica Organica e Biologica, Università degli Studi di Messina, Salita \\ Sperone 31 (vill. S. Agata), I-98166 Messina, Italy \\ ${ }^{b}$ Institut de Chimie Organique et Analytique, UMR 6005, Université d'Orléans, BP 6759, \\ F-45067 Orléans Cedex 2, France \\ E-mail: anna.barattucci@unime.it
}

This paper is dedicated to Professor Nicolò Vivona on the occasion of his $70^{\text {th }}$ birthday

\begin{abstract}
The use of 2,2-bis(phenylsulfonyl)ethyl sulfides as efficient precursors of sulfenic acids is reported. These starting compounds, carrying both sulfone and sulfide residues, are obtained in one step from commercially available thiols and 1,1-bis(phenylsulfonyl)ethylene. Mild decomposition of the derived 2,2-bis(phenylsulfonyl)ethyl sulfoxides to sulfenic acids, in the presence of suitable acceptors, opens the way to the generation of a wide library of new sulfoxides not easily accessible through different synthetic pathways.
\end{abstract}

Keywords: 1,1-Bis(phenylsulfonyl)ethylene, $\beta$-syn-addition, $\beta$-syn-elimination, sulfenic acids

\section{Introduction}

Sulfenic acids 1 are generally transient species (Scheme 1), not isolable when no stabilizing structural feature is present in the R moiety directly linked to the sulfur atom. ${ }^{1}$

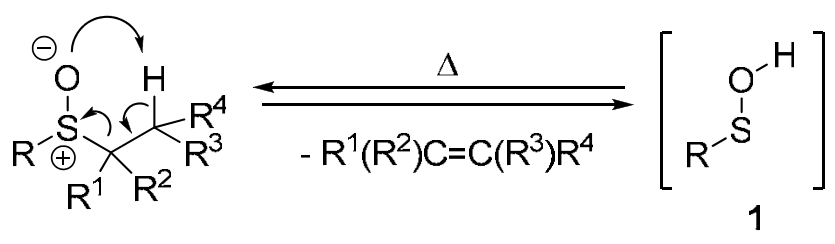

\section{Scheme 1}


Many methods are reported in the literature ${ }^{2}$ for the in situ generation of $\mathbf{1}$. The most exploited procedure is the thermolysis of suitable sulfoxides: this reaction is an intramolecular $\beta$ syn-elimination, that often happens at high temperatures, and follows a concerted mechanism (Scheme 1).

The temperature of the sulfoxide decomposition into sulfenic acid and alkene depends on the mobility of the hydrogens in $\beta$-position to the sulfinyl moiety. The presence of one or two electron-withdrawing groups directly linked to the $\beta$-carbon enhances the mobility of this hydrogen atom, ${ }^{3}$ consequently lowering the activation energy of the decomposition. The transient sulfenic acid can add, once formed, to unsaturations, carbon-carbon double or triple bonds, via a syn-addition concerted mechanism, to produce various kinds of functionalized sulfoxides in regio- and stereo-selective manner, if the case. When the sulfenic acid bears at least one stereogenic structural feature, two sulfur epimers are formed, in some cases with a certain stereoselection. $^{4}$ These sulfoxides can easily be separated to constitute enantiopure starting products of many stereoselective reactions where the sulfoxide moiety acts as chiral auxiliary. ${ }^{5}$

Since the ' $90 \mathrm{~s}$ part of our chemistry has been devoted to the employment of thiofunctionalized compounds in the synthesis of molecules of applicative interest. ${ }^{6}$ In many cases the key step of the procedure has been the concerted syn-addition of sulfenic acids $\mathbf{1}$ to unsaturated systems. If severe conditions are needed for the thermolysis step - sulfenic acid formation / addition to unsaturation as a unique domino process - the yields of the desired products are notably affected. In fact, elevated temperatures favour the self-condensation of the sulfenic acids as well as their redox transformations. ${ }^{7}$

Finally, most of the reported syntheses involving sulfenic acid intermediation lead to the formation of vinyl sulfoxides, resulting from sulfenic acid addition on an alkyne, while only few cases involving the addition of $\mathbf{1}$ to double bonds are reported. ${ }^{2}$

This paper intends to demonstrate the central importance of 1,1-bis(phenylsulfonyl)ethylene (2) as a key reagent in the generation of sulfenic acids. The conversion of the sulfinyl precursors takes place even at room temperature (RT), thus limiting the formation of side products to very low yields. Moreover the mildness of the reaction conditions allows the easy addition of the intermediate sulfenic acid even to double bonds, in quantitative yields.

\section{Results and Discussion}

The first step of our project has been the preparation of sulfides 5 by reacting thiols 4 with an almost equimolar amount of strongly electrophilic 1,1-bis(phenylsulfonyl)ethylene (2) ${ }^{8}$ in the presence of Triton B as a base (Scheme 2). ${ }^{9}$ In order to evaluate the applicability of the method, four thiols have been chosen as models: an aliphatic one [cyclohexanethiol (4a)], an aromatic one [benzenethiol (4b)], phenylmethanethiol (4c), and $N$-(tert-butoxycarbonyl)-L-cysteine methyl ester (4d). 


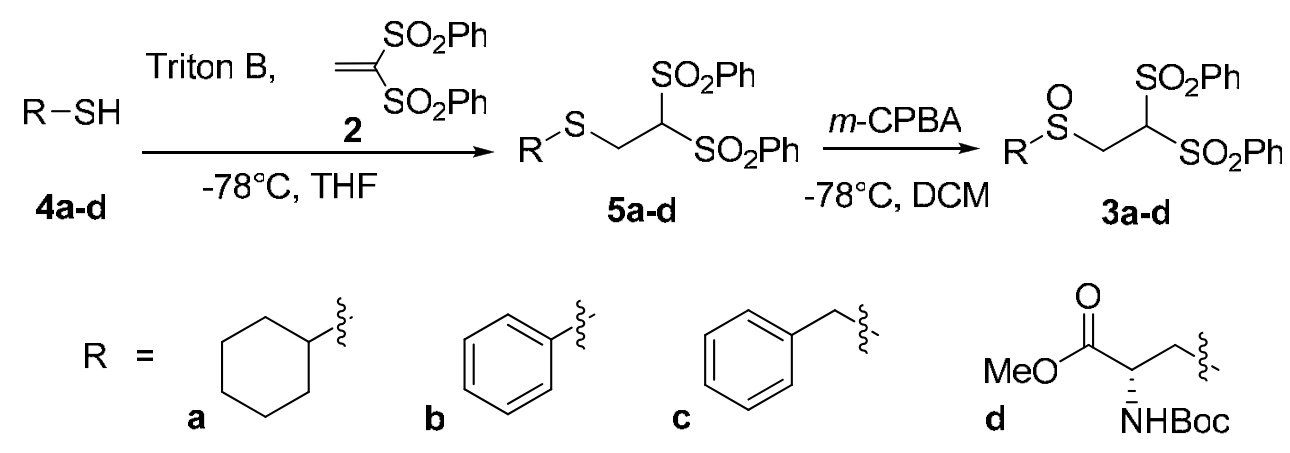

Scheme 2

The nucleophilic addition of the obtained thiolate to the electron-poor unsaturation of 2 led to the formation of bis-sulfone sulfides 5 in quantitative yields. Subsequent controlled oxidation of 5 with meta-chloroperoxybenzoic acid ( $m$-CPBA) at $-78{ }^{\circ} \mathrm{C}$ gave sulfoxides 3 within a few minutes (Scheme 2).

In order to evaluate the capability of the newly formed sulfinyl systems in being good sulfenic acid precursors, sulfoxides $\mathbf{3 b}$ (racemic mixture) was thermolyzed in the presence of a typical alkyne acceptor, dimethyl acetylenedicarboxylate (DMAD, Scheme 3).

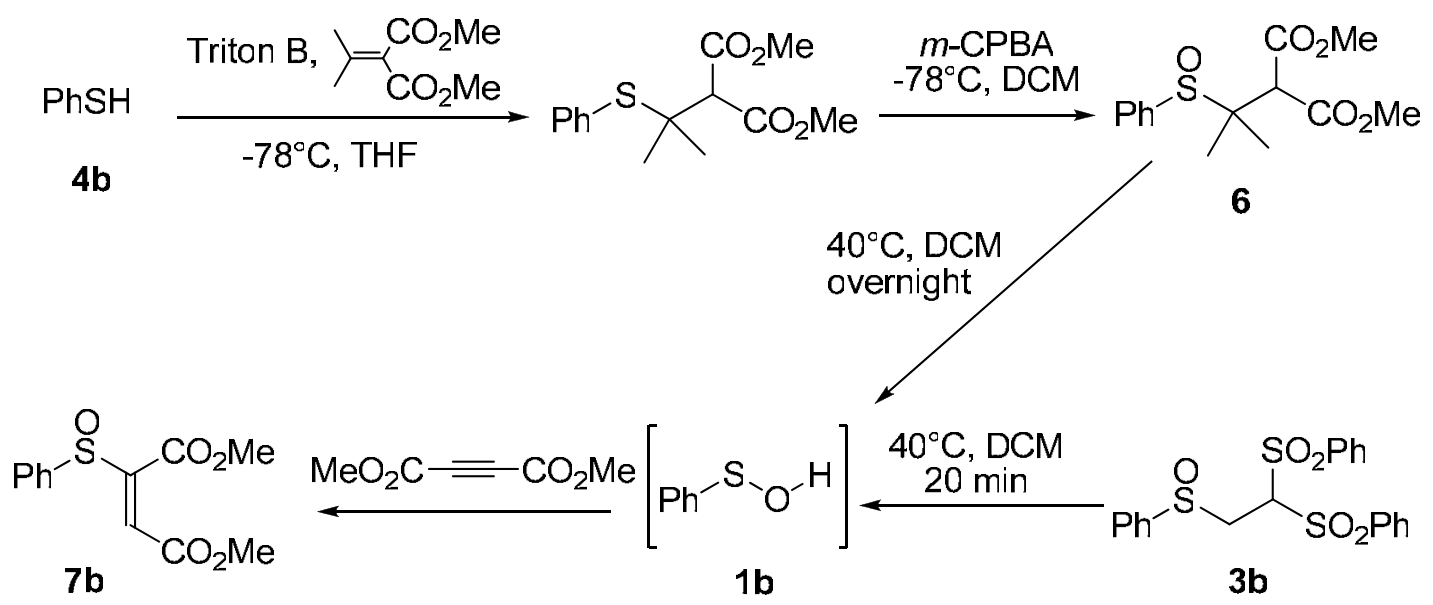

\section{Scheme 3}

The reaction was performed in dichloromethane $(\mathrm{DCM})$ at $40^{\circ} \mathrm{C}$, in the presence of an excess (1:6) of acceptor, using TLC to follow the consumption of the starting products $3 \mathbf{b}$.

The results obtained from the thermolysis of sulfoxides $\mathbf{3 b}$ in the presence of DMAD, in terms of reaction times and yields of the final addition products $\mathbf{7 b}$, were compared with those obtained from sulfoxides 6 (racemic mixture), coming from the synthetic path shown in Scheme $3 .^{3}$ In both cases the vinyl sulfoxides $\mathbf{7 b}$ (racemic mixture) were the main products. The great difference in the reaction times between $3 \mathbf{b}$ and 6 (20 min versus $12 \mathrm{~h}$ ), both in DCM, at $40{ }^{\circ} \mathrm{C}$ and with the same sulfoxide/DMAD molar ratio (1:6), gave us the confirmation that the 
thermolysis of the sulfoxide precursor is the rate limiting step of the total process and that the new precursor $\mathbf{3 b}$ requires shorter time with respect to $\mathbf{6}$ for decomposition to sulfenic acid $\mathbf{1 b}$. This means that the two geminal sulfonyl groups render the $\beta$-hydrogen more mobile than in many other known starting products. All the sulfoxides 3 reacted in the same conditions, giving the addition products $\mathbf{7 a - d ,}$ with comparable reaction times. Results are reported in Table 1 (entries $1,4,9,12$ ). The first outcome of these results is that sulfoxides 3 are too reactive to be stored, and therefore they have to be utilized as a crude in the subsequent reaction, at once after their formation by sulfide oxidation.

Table 1. Syn-additions of sulfenic acids 1a-d onto alkyne and alkene acceptors.

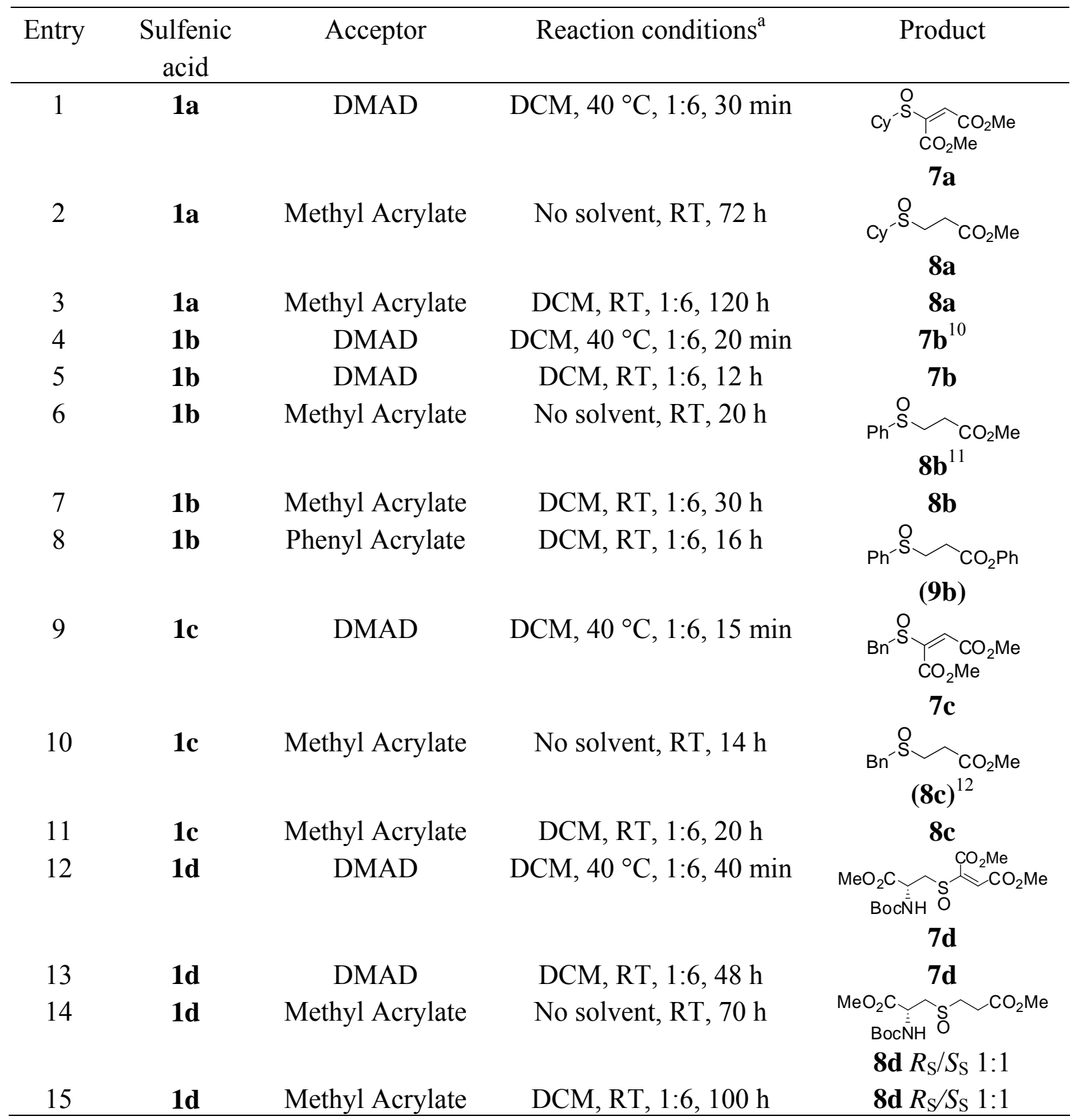


Table 1. Continued

\begin{tabular}{|c|c|c|c|c|}
\hline 16 & 1d & Phenyl Acrylate & DCM, RT, 1:6, $60 \mathrm{~h}$ & 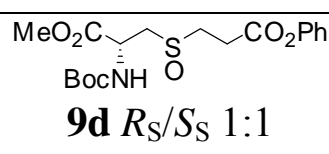 \\
\hline 17 & 1d & 11 & DCM, RT, 6:1, $72 \mathrm{~h}$ & 12 \\
\hline
\end{tabular}

${ }^{a}$ Solvent, temperature, sulfoxide/acceptor molar ratio, reaction time.

This result could appear, at first sight, a limitation to our synthetic process. In other respects, the very high yields observed for the final vinyl sulfoxides 7 prompted us to test the same process, but in milder conditions. Kept in the presence of DMAD in the same sulfoxide/acceptor molar ratio 1:6 at RT, crude $3 \mathbf{b}$ led after 6 h to vinyl sulfoxides $7 \mathbf{b}$ in quantitative yield (Table 1, entry 5). No products originated by self-condensation of $\mathbf{1 b}$ were isolated, thus demonstrating that the mild conditions applied for sulfenic acid generation are also optimal for the addition step.

The same method was applied for the addition to double bonds. In fact, while the addition reaction of sulfenic acids to triple bonds has largely been exploited in the synthesis of vinyl sulfoxides, a comment must be made about the addition to the carbon-carbon double bonds. In this last case the syn-addition has to obey to more strict steric demands and, before the sulfenic intermediate can succeed in reaching the unsaturation in a proper geometry, it can easily undergo self-condensation to produce thiosulfinates. ${ }^{2,13}$ For this reason very few are the examples of efficient syntheses of sulfoxides via sulfenic acid / alkene concerted syn-addition, most of them being intramolecular, because of the easier accessibility of a close double bond to be attached. ${ }^{14}$ Otherwise, most of the reported examples of intermolecular addition of sulfenic acids to double bonds involve electron-poor unsaturations: it is suggested that in such cases the reaction follows a less-concerted, dipolar-like mechanism. ${ }^{13}$

Sulfoxides 3 were then reacted at RT in neat methyl acrylate (Table 1, entries 2, 6, 10, 14), and the unique products obtained in quantitative yields were the methyl 3-sulfinylpropanoates 8 resulting from the completely regioselective syn-addition of the sulfenic acids onto the electronpoor double bond. All the reactions performed in neat acceptor have been repeated in DCM, still at RT, with acrylate in excess (1:6) (Table 1, entries 3, 7, 11, 15). Those experiments aimed at estimating whether the sulfenic acid could attack the double bond even when not completely surrounded by the acceptor, but only in the presence of a reasonable molar excess: the yields compare with those obtained in neat acceptor, whereas reaction times are more or less doubled.

The above results bring confirmation that the method could be applied even in the presence of more expensive or not commercially available unsaturated acceptors, and this opens the way to many more applications. As reported in Table 1 , also the reactions of $\mathbf{3 b}, \mathbf{d}$ in the presence of phenyl acrylate ${ }^{15}$ gave good results (entries 8 and 16, products $9 \mathbf{b}, \mathbf{d}$ ). These findings are consistent with the smooth generation of the four sulfenic acids 1a-d and their clean addition to the double bond of both the acrylates. 
A particular comment must be devoted to $\mathbf{3 d}$, a case where two non-equivalent $\beta$-hydrogens are available with respect to the sulfoxide group, as already reported in our previous papers (Scheme 4). ${ }^{6 a-c}$

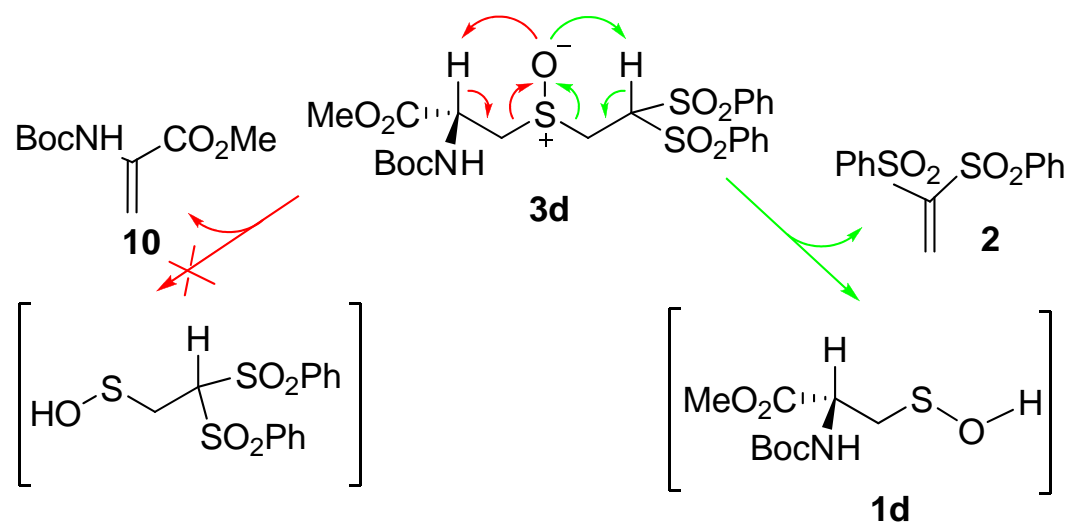

\section{Scheme 4}

Besides self-condensation of 1d, another side reaction is then expected to happen: the generation of a different competing sulfenic acid. The same situation having appeared in our previous works, ${ }^{6 \mathrm{~b}}$ we had overcome the problem by using a precursor which could undergo thermolysis at $40{ }^{\circ} \mathrm{C}$, thus minimizing formation of the undesired sulfenic acid. That was confirmed by the inspection of the ${ }^{1} \mathrm{H}$ NMR spectra of the crudes of our reactions of 3d with different sulfenic acid acceptors, all indicating the absence of the amino ester 10 (Scheme 4).

In order to apply our method to the elaboration of new classes of three-branched molecules ${ }^{6 \mathrm{~d}}$ containing sulfinyl or sulfonyl moieties we thought to synthesize trissulfoxides 12 (Scheme 5). The reaction of a six-fold excess of $\mathbf{3 d}$ [precursor of (R)-2-(tert-butoxycarbonylamino)-2(methoxycarbonyl)ethanesulfenic acid (1d)] with trisacrylate $\mathbf{1 1}^{16}$ has been conducted in DCM at RT (Table 1, entry 17). 


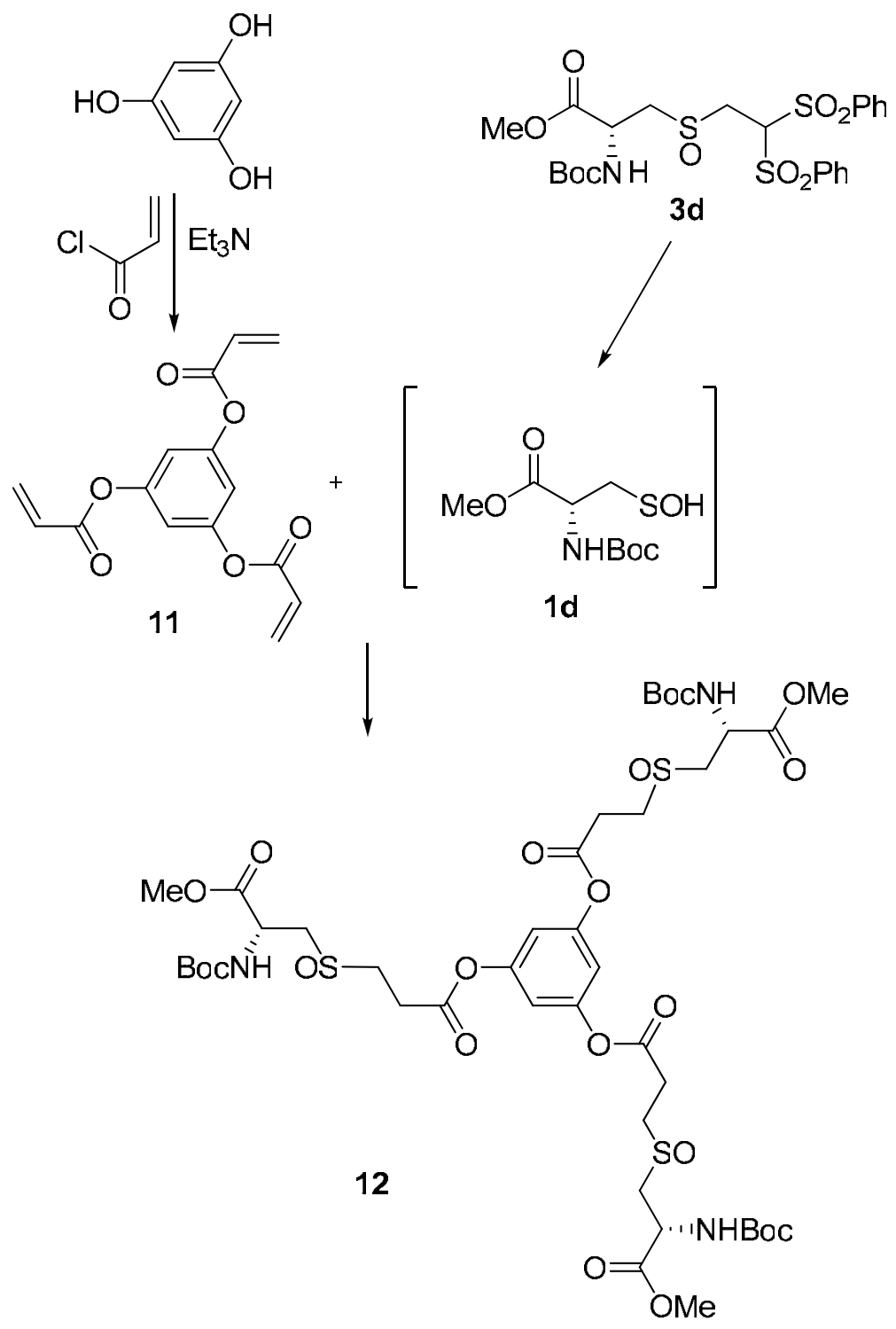

Scheme 5

The first results of this reaction show the formation of a mixture of diastereoisomeric sulfoxides 12, resulting from the completely regioselective addition of the sulfenic acid 1d onto the three vinyl groups in 11. In a first approach, the diastereomeric mixture $\mathbf{1 2}$ will be oxidized to a unique tris-sulfone, in order to rid ourselves of the sulfur stereogenicity. The next step will involve deprotection of amino and carboxyl moieties in the tris-sulfone, and evaluation of the biological activity of the enantiopure derivative obtained.

\section{Conclusions}


The Table 1 shows the good results obtained in synthesizing various sulfoxides 7-9 and 12 drawing advantage from the chemistry of sulfenic acids 1 . Mild conditions required by the procedure and high yields observed support the validity of 2,2-bis(phenylsulfonyl)ethyl sulfides and their sulfoxide derivatives as efficient precursors of sulfenic acids generated by intramolecular $\beta$-syn-elimination.

\section{Experimental Section}

General Procedures. Solvents were purified according to standard procedures. Petroleum ether used refers to the fraction boiling at $30-50{ }^{\circ} \mathrm{C}$. All reactions were monitored by TLC on commercially available precoated plates (Aldrich silica gel $60 \mathrm{~F} \mathrm{254)}$ ) and the products were visualized with vanillin $\left[1 \mathrm{~g}\right.$ dissolved in $\mathrm{MeOH}(60 \mathrm{ml})$ and conc. $\left.\mathrm{H}_{2} \mathrm{SO}_{4}(0.6 \mathrm{ml})\right]$ : the reported $R f$ refer to EtOAc / petroleum ether 3:2 as eluent, unless otherwise stated. Silica gel used for column chromatography was Aldrich $60 .{ }^{1} \mathrm{H}$ and ${ }^{13} \mathrm{C}$ NMR spectra were recorded on a Varian Mercury 300 spectrometer at 300 and $75 \mathrm{MHz}$ respectively in $\mathrm{CDCl}_{3}$ solutions with $\mathrm{SiMe}_{4}$ as internal standard: $J$ values are given in $\mathrm{Hz}$; the attributions are supported by Attached Proton Test (APT) and homodecoupling experiments.

Formation of sulfides 5a-d. General procedure. To a $2 \mathrm{M}$ solution of commercial thiols 4a-d in anhydrous tetrahydrofuran (THF), at $-78{ }^{\circ} \mathrm{C}$ under argon atmosphere and continuous stirring, Triton B was added (40\% wt MeOH sol., thiol 4 / Triton B molar ratio 1:0.12). After 5 min stirring a $2 \mathrm{M}$ THF solution of 2 (4/2 molar ratio 1:1.2) was slowly added. The reaction was monitored by TLC (EtOAc / petroleum ether 1:3), to follow consumption of the starting product 4a-d. After completion, brine was added, the reaction mixture was extracted with DCM, and the collected extracts washed twice with brine. After drying over $\mathrm{Na}_{2} \mathrm{SO}_{4}$, the solution was filtered and concentrated under reduced pressure to give the reaction crude, then submitted to chromatographic purification (EtOAc / petroleum ether 1:3). All yields were almost quantitative. The characterization of sulfides $\mathbf{5 a , b}$ was consistent with the data reported in the literature. ${ }^{17}$ 1,1-Bis(phenylsulfonyl)-2-(benzylsulfanyl)ethane (5c). Light yellow solid, m.p. 94-97 ${ }^{\circ} \mathrm{C}$. TLC: $R f$ 0.87. ${ }^{1} \mathrm{H}$ NMR: $\delta 7.8-7.2\left(\mathrm{~m}, 15 \mathrm{H}, \mathrm{H}_{\text {arom }}\right), 4.40\left(\mathrm{t}, J_{1,2} 6.0,1 \mathrm{H}, \mathrm{H}-1\right), 3.70(\mathrm{~s}, 2 \mathrm{H}$, $\mathrm{PhCH}_{2}$ ), 3.21 (d, 2H, $\left.\mathrm{H}_{2}-2\right) .{ }^{13} \mathrm{C}$ NMR: $\delta 137.7,137.2,136.5,134.9,134.5,129.4,129.3,129.1$, 128.9, 128.7, 128.5, 128.3, 127.1, and $127.0\left(\mathrm{C}_{\text {arom }}\right), 83.9(\mathrm{C}-1), 37.5\left(\mathrm{PhCH}_{2}\right), 26.8(\mathrm{C}-2)$. Anal. calcd. for $\mathrm{C}_{21} \mathrm{H}_{20} \mathrm{O}_{4} \mathrm{~S}_{3}$ (432.58): C, 58.31; H, 4.66\%. Found: C, 58.33; H, 4.63\%.

\section{1,1-Bis(phenylsulfonyl)-2-[(R)-2-(tert-butoxycarbonylamino)-2-}

(methoxycarbonyl)ethylsulfanyl]ethane (5d). Transparent oil. TLC: $R f$ 0.75. ${ }^{1} \mathrm{H}$ NMR: $\delta$ 8.0$7.5\left(\mathrm{~m}, 10 \mathrm{H}, \mathrm{H}_{\text {arom }}\right.$ ), 5.29 (br d, $\left.J_{\text {vic }} 5.8,1 \mathrm{H}, \mathrm{NH}\right), 4.93$ (br t, $\left.J_{1,2} 5.6,1 \mathrm{H}, \mathrm{H}-1\right), 4.43$ (dd, $J_{\text {vic }} 6.2$ and 4.7, $1 \mathrm{H}, \mathrm{NCH}), 3.76(\mathrm{~s}, 3 \mathrm{H}, \mathrm{OMe}), 3.34\left(\mathrm{~d}, 2 \mathrm{H}, \mathrm{H}_{2}-2\right), 2.98$ and 2.83 (split AB system, $J_{\text {gem }}$ 14.2, 2H, $\left.\mathrm{NCHCH}_{2}\right), 1.46\left(\mathrm{~s}, 9 \mathrm{H}, \mathrm{CMe}_{3}\right) .{ }^{13} \mathrm{C} \mathrm{NMR}: \delta 171.1\left(\mathrm{CO}_{2} \mathrm{Me}\right), 155.1(\mathrm{OCONH}), 137.6$, 
137.5, 134.7, 129.6, 129.1, and $129.0\left(\mathrm{C}_{\text {arom }}\right), 84.3(\mathrm{C}-1), 80.3\left(\mathrm{CMe}_{3}\right), 53.0$ and $52.7(\mathrm{NCH}$ and $\mathrm{OMe}), 36.7\left(\mathrm{NCHCH}_{2}\right), 28.2\left(\mathrm{CMe}_{3}\right), 27.7$ (C-2). Anal. calcd. for $\mathrm{C}_{23} \mathrm{H}_{29} \mathrm{NO}_{8} \mathrm{~S}_{3}$ (543.67): C, $50.81 ; \mathrm{H}, 5.38 ; \mathrm{N}, 2.58 \%$. Found: C, 50.84; H, 5.41; N, 2.56\%.

Oxidation of sulfides $5 a-d$ to sulfoxides 3a-d. General procedure. To a stirred $0.2 \mathrm{M}$ solution of 5a-d in DCM, at $-78{ }^{\circ} \mathrm{C}$, a DCM 0.2 M solution of an equimolar amount of $m$-CPBA was added. The reaction was followed by TLC (EtOAc / petroleum ether 1:1) until complete transformation of the sulfide. A $10 \%$ wt aqueous solution of $\mathrm{Na}_{2} \mathrm{~S}_{2} \mathrm{O}_{3}$ was added, and the mixture maintained under stirring until it reached RT. The inorganic layer was discarded and the organic phase was washed twice with aqueous sat. $\mathrm{NaHCO}_{3}$, then twice with brine. After drying over $\mathrm{Na}_{2} \mathrm{SO}_{4}$, the solvent was removed in vacuo and the crude oil used at once in the subsequent thermolysis reaction.

1,1-Bis(phenylsulfonyl)-2-(cyclohexylsulfinyl)ethanes 3a (racemic mixture). TLC: $R f$ 0.42. ${ }^{1} \mathrm{H}$ NMR: $\delta$ 8.0-7.5 (m, 10H, $\mathrm{H}_{\text {arom }}$ ), 5.29 (dd, $J_{1,2} 7.5$ and 4.0, 1H, H-1), $3.52\left(\mathrm{~m}, 2 \mathrm{H}, \mathrm{H}_{2}-2\right), 2.57$ (m, 1H, Cy CHS), 2.1-1.2 (m, 10H, 5 x $\mathrm{Cy} \mathrm{CH}_{2}$ ).

1,1-Bis(phenylsulfonyl)-2-(phenylsulfinyl)ethanes $3 b$ (racemic mixture). TLC: $R f$ 0.40. ${ }^{1} \mathrm{H}$ NMR: $\delta$ 8.0-7.5 (m, 15H, $\left.\mathrm{H}_{\text {arom }}\right), 5.11\left(\mathrm{dd}, J_{1,2} 8.5\right.$ and 3.5, $\left.1 \mathrm{H}, \mathrm{H}-1\right), 3.57$ and 3.51 (split AB system, $\left.J_{2 \mathrm{~A}, 2 \mathrm{~B}} 14.0,2 \mathrm{H}, \mathrm{H}_{2}-2\right)$.

1,1-Bis(phenylsulfonyl)-2-(benzylsulfinyl)ethanes 3c (racemic mixture). TLC: $R f \quad 0.38$. ${ }^{1} \mathrm{H}$ NMR: $\delta$ 7.9-7.3 (m, 15H, $\mathrm{H}_{\text {arom }}$ ), $5.23\left(\mathrm{dd}, J_{1,2} 8.3\right.$ and 3.4, 1H, H-1), 4.12 and 4.06 (AB system, $J_{\text {gem }} 13.0,2 \mathrm{H}, \mathrm{PhCH}_{2}$ ), 3.43 and 3.38 (split AB system, $J_{2 \mathrm{~A}, 2 \mathrm{~B}} 14.5,2 \mathrm{H}, \mathrm{H}_{2}-2$ ).

1,1-Bis(phenylsulfonyl)-2-[(R)-2-(tert-butoxycarbonylamino)-2-

(methoxycarbonyl)ethylsulfinyl]ethanes $3 \mathbf{d}$ (1:1 S-epimeric mixture). TLC: $R f \quad 0.38$. ${ }^{1} \mathrm{H}$ NMR: $\delta$ 7.9-7.5 (m, 10H, $\left.\mathrm{H}_{\text {arom }}\right), 5.54(\mathrm{~m}, 1 \mathrm{H}, \mathrm{NH}), 5.24(\mathrm{~m}, 1 \mathrm{H}, \mathrm{H}-1), 4.65(\mathrm{~m}, 1 \mathrm{H}, \mathrm{NCH}), 3.80$ and 3.78 (two s, 3H, OMe), 3.8-3.2 (m, 4H, $\mathrm{NCHCH}_{2}$ and $\mathrm{H}_{2}-2$ ), 1.46 and 1.45 (two s, 9H, $\left.\mathrm{CMe}_{3}\right)$.

2-Propenoic acid 1,3,5-benzenetriyl ester (11). Prepared according to a previously reported procedure, ${ }^{16}$ purified by very rapid flash chromathography and used immediately in the thermolysis reaction. TLC: $R f$ (EtOAc / petroleum ether 1:1) 0.86. ${ }^{1} \mathrm{H}$ NMR: $\delta 6.96(\mathrm{~s}, 3 \mathrm{H}$, $\mathrm{H}_{\text {arom }}$ ), 6.61 (dd, J(trans) $\left.)_{2,3 \mathrm{~A}} 17.2, J_{3 \mathrm{~A}, 3 \mathrm{~B}} 1.3,3 \mathrm{H}, 3 \mathrm{x} \mathrm{H}_{\mathrm{A}}-3\right), 6.29$ (dd, $J(\text { cis) })_{2,3 \mathrm{~B}} 10.5,3 \mathrm{H}, 3 \times \mathrm{H}-$ 2), $6.03\left(\mathrm{dd}, 3 \mathrm{H}, 3 \times \mathrm{H}_{\mathrm{B}}-3\right)$.

Thermolysis of sulfoxides 3a-d in the presence of DMAD, methyl and phenyl acrylate, 2propenoic acid 1,3,5-benzenetriyl ester (11). General procedure. A 0.2 M DCM solution of 3 was added, under continous stirring, of an excess of alkyne or alkene acceptor (1:6 molar ratio); then the reaction was maintained under stirring at RT or under reflux (Table 1). When the reaction appeared complete by TLC (consumption of 3, EtOAc / petroleum ether 1:1, see reaction times in Table 1), the reaction crude was purified by flash column chromatography on silica gel (EtOAc / petroleum ether from 1:9 to 1:1). The yields were always $>70 \%$. The 
characterization of the obtained sulfoxides $\mathbf{7 b}$ and $\mathbf{8 b}, \mathbf{c}$ was consistent with the data reported by the literature. ${ }^{10-12}$

(E)-2-(Cyclohexylsulfinyl)-2-butenedioic acids dimethyl esters 7a (racemic mixture). Transparent oil. TLC: $R f$ 0.79. ${ }^{1} \mathrm{H}$ NMR: $\delta 6.69(\mathrm{~s}, 1 \mathrm{H}, \mathrm{H}-3$ ), 3.87 and 3.82 (two s, $6 \mathrm{H}, 2 \mathrm{x}$ OMe), 2.72 (tt, $J_{\text {vic }} 12.2$ and 3.6, $\left.1 \mathrm{H}, \mathrm{Cy} \mathrm{CHS}\right), 2.1-1.1\left(\mathrm{~m}, 10 \mathrm{H}, 5 \times \mathrm{CH}_{2}\right) .{ }^{13} \mathrm{C} \mathrm{NMR}: \delta 164.2$ and 162.4 (C-1,4), 148.2 (C-2), 128.5 (C-3), 58.8 (Cy CHS), 53.2 and 52.6 (2 x OMe), 27.6, 25.9, 25.2, 25.0, and $21.5\left(5 \mathrm{x} \mathrm{CH}_{2}\right)$. Anal. calcd. for $\mathrm{C}_{12} \mathrm{H}_{18} \mathrm{O}_{5} \mathrm{~S}(274.33)$ : C, 52.54; $\mathrm{H}, 6.61 \%$. Found: C, 52.55; H, 6.59\%.

(E)-2-(Benzylsulfinyl)-2-butenedioic acids dimethyl esters 7c (racemic mixture). Transparent oil. TLC: $R f$ 0.77. ${ }^{1} \mathrm{H}$ NMR: $\delta$ 7.4-7.2 (m, 5H, $\mathrm{H}_{\text {arom}}$ ), 6.49 (s, 1H, H-3), 4.29 and 4.03 (AB system, $J_{\text {gem }} 13.1,2 \mathrm{H}, \mathrm{CH}_{2}$ ), 3.87 and 3.79 (two s, $6 \mathrm{H}, 2$ x OMe). ${ }^{13} \mathrm{C}$ NMR: $\delta 164.3$ and 162.5 (C-1,4), 147.3 (C-2), 130.7, 130.2, 129.6, 129.4, 128.7, and $128.5\left(\mathrm{C}_{\text {arom }}\right.$ and $\left.\mathrm{C}-3\right), 59.4\left(\mathrm{CH}_{2}\right)$, 53.2 and 52.6 (2 x OMe). Anal. calcd. for $\mathrm{C}_{13} \mathrm{H}_{14} \mathrm{O}_{5} \mathrm{~S}$ (282.31): C, 55.31; H, 5.00\%. Found: C, $55.32 ; \mathrm{H}, 4.98 \%$.

(E)-2-[(R)-2-(tert-Butoxycarbonylamino)-2-(methoxycarbonyl)ethylsulfinyl]-2-butenedioic acids dimethyl esters 7d (1:1 S-epimeric mixture). Transparent oil. TLC: $R f 0.65 .{ }^{1} \mathrm{H}$ NMR: $\delta$ 6.95 and 6.90 (two s, 1H, H-3), $5.59(\mathrm{~m}, 1 \mathrm{H}, \mathrm{NH}), 4.66(\mathrm{~m}, 1 \mathrm{H}, \mathrm{NCH}), 3.87,3.85$, and 3.79 (three s, 9H, 3 x OMe), 3.8-3.2 (m, 2H, $\left.\mathrm{CH}_{2}\right), 1.45\left(\mathrm{~s}, 9 \mathrm{H}, \mathrm{CMe}_{3}\right) .{ }^{13} \mathrm{C} \mathrm{NMR:} \delta 170.4,170.2$, and $164.4\left(\mathrm{C}-1,4\right.$ and $\left.\mathrm{CO}_{2} \mathrm{Me}\right), 147.6$ and $147.5(\mathrm{C}-2$ and $\mathrm{OCONH}), 129.7(\mathrm{C}-3), 80.7\left(\mathrm{CMe}_{3}\right), 58.4$ and $54.3\left(\mathrm{CH}_{2}\right), 53.3,53.0,52.7,49.7$, and 49.1 ( $\mathrm{NCH}$ and $\left.3 \mathrm{x} \mathrm{OMe}\right), 28.2$ and $28.1\left(\mathrm{CMe}_{3}\right)$. Anal. calcd. for $\mathrm{C}_{15} \mathrm{H}_{23} \mathrm{NO}_{9} \mathrm{~S}$ (393.41): C, 45.79; H, 5.89; N, 3.56\%. Found: C, 45.82; H, 5.89; N, $3.59 \%$.

3-(Cyclohexylsulfinyl)propanoic acids methyl esters 8a (racemic mixture). Light yellow solid, m.p. 105-107 ${ }^{\circ} \mathrm{C}$. TLC: $R f$ 0.21. ${ }^{1} \mathrm{H}$ NMR: $\delta 3.70$ (s, 3H, OMe), 3.0-2.8 (m, 4H, $\mathrm{H}_{2}-2,3$ ), $2.56\left(\mathrm{tt}, J_{\text {vic }} 11.3\right.$ and 3.4, $\left.\left.1 \mathrm{H}, \mathrm{Cy} \mathrm{CHS}\right), 2.2-1.2(\mathrm{~m}, 10 \mathrm{H}, 5 \mathrm{x} \mathrm{Cy} \mathrm{CH})^{2}\right) .{ }^{13} \mathrm{C} \mathrm{NMR}: \delta 171.9(\mathrm{C}-1)$, $59.4(\mathrm{CH}), 52.1$ (OMe), 43.6 (C-3), 27.1, 26.2, 25.4, 25.3, and 25.0 (C-2 and $\left.5 \mathrm{x} \mathrm{Cy} \mathrm{CH}_{2}\right)$. Anal. calcd. for $\mathrm{C}_{10} \mathrm{H}_{18} \mathrm{O}_{3} \mathrm{~S}$ (218.31): C, 55.02; H, 8.31\%. Found: C, 55.02; H, 8.33\%.

3-[(R)-2-(tert-Butoxycarbonylamino)-2-(methoxycarbonyl)ethylsulfinyl]propanoic acids methyl esters 8d (1:1 S-epimeric mixture). Transparent oil. TLC: $R f 0.26 .{ }^{1} \mathrm{H}$ NMR: $\delta 5.80$ and 5.70 (two br d, $J_{\text {vic }} 7.8,1 \mathrm{H}, \mathrm{NH}$ ), $4.69(\mathrm{~m}, 1 \mathrm{H}, \mathrm{NCH}$ ), 3.80, 3.79, 3.74, and 3.73 (four s, $6 \mathrm{H}, 2 \mathrm{x}$ $\mathrm{OMe}), 3.4-2.8\left(\mathrm{~m}, 6 \mathrm{H}, 3 \times \mathrm{CH}_{2}\right), 1.45$ (s, 9H, $\left.\mathrm{CMe}_{3}\right) .{ }^{13} \mathrm{C} \mathrm{NMR}: \delta 171.6,171.5,170.7$, and 170.4 $\left(2 \times \mathrm{CO}_{2} \mathrm{Me}\right), 154.5$ and $154.2(\mathrm{OCONH}), 80.5\left(\mathrm{CMe}_{3}\right), 54.3$ and $53.5\left(\mathrm{NCHCH}_{2}\right), 53.0,52.9$, 52.2, 50.0, and 49.6 ( $\mathrm{NCH}$ and $2 \mathrm{x} \mathrm{OMe}), 47.4$ and $47.0(\mathrm{C}-3), 28.1\left(\mathrm{CMe}_{3}\right), 26.7$ and $23.6(\mathrm{C}-2)$. Anal. calcd. for $\mathrm{C}_{13} \mathrm{H}_{23} \mathrm{NO}_{7} \mathrm{~S}$ (337.39): C, 46.28; H, 6.87; N, 4.15\%. Found: C, 46.24; H, 6.87; N, $4.17 \%$.

3-(Phenylsulfinyl)propanoic acids phenyl esters 9b (racemic mixture). Transparent oil. TLC: Rf 0.64. ${ }^{1} \mathrm{H}$ NMR: $\delta$ 7.5-7.0 (m, 10H, $\mathrm{H}_{\text {arom }}$ ), 3.4-2.8 (m, 4H, $\left.\mathrm{H}_{2}-2,3\right) .{ }^{13} \mathrm{C}$ NMR: $\delta 169.9(\mathrm{C}-1)$, 150.4 and 142.7 (quaternary $\mathrm{C}_{\text {arom }}$ ), 131.2, 129.4, 129.3, 129.1, 126.0, 124.0, and $121.3\left(\mathrm{CH}_{\text {arom }}\right)$, 50.8 (C-3), 26.2 (C-2). Anal. calcd. for $\mathrm{C}_{15} \mathrm{H}_{14} \mathrm{O}_{3} \mathrm{~S}$ (274.33): C, 65.67; H, 5.14\%. Found: C, 65.6; $\mathrm{H}, 5.16 \%$. 
3-[(R)-2-(tert-Butoxycarbonylamino)-2-(methoxycarbonyl)ethylsulfinyl]propanoic acids phenyl esters 9d (1:1 S-epimeric mixture). Low melting white solid. TLC: $R f 0.45$. ${ }^{1} \mathrm{H}$ NMR: $\delta$ 7.4-7.1 (m, 5H, $\mathrm{H}_{\text {arom }}$ ), $5.67(\mathrm{~m}, 1 \mathrm{H}, \mathrm{NH}), 4.70(\mathrm{~m}, 1 \mathrm{H}, \mathrm{NCH}), 3.81$ and 3.79 (two s, $3 \mathrm{H}, \mathrm{OMe}$ ), 3.4-3.0 (m, 6H, $\left.3 \times \mathrm{CH}_{2}\right), 1.45$ (s, 9H, $\left.\mathrm{CMe}_{3}\right) .{ }^{13} \mathrm{C}$ NMR: $\delta 170.3$ and $169.8\left(\mathrm{C}-1\right.$ and $\left.\mathrm{CO}_{2} \mathrm{Me}\right)$, 155.3 and 150.4 (quaternary $\mathrm{C}_{\text {arom }}$ and $\left.\mathrm{OCONH}\right), 129.5,126.1$, and $121.3\left(\mathrm{CH}_{\text {arom }}\right), 80.7\left(\mathrm{CMe}_{3}\right)$, $54.4\left(\mathrm{NCHCH}_{2}\right), 53.1,53.0,50.1$ and $49.7(\mathrm{NCH}$ and $\mathrm{OMe}), 47.3$ and $46.8(\mathrm{C}-3), 28.2\left(\mathrm{CMe}_{3}\right)$, 27.1 and 27.0 (C-2). Anal. calcd. for $\mathrm{C}_{18} \mathrm{H}_{25} \mathrm{NO}_{7} \mathrm{~S}$ (399.46): $\mathrm{C}, 54.12 ; \mathrm{H}, 6.31 ; \mathrm{N}, 3.51 \%$. Found: C, $54.08 ; \mathrm{H}, 6.30 ; \mathrm{N}, 3.54 \%$.

3-[(R)-2-(tert-Butoxycarbonylamino)-2-(methoxycarbonyl)ethylsulfinyl]propanoic acids 1,3,5-benzenetriyl esters 12 (diastereomeric mixture). Low melting yellow solid. TLC: $R f$ (EtOAc) 0.10. ${ }^{1} \mathrm{H}$ NMR: $\delta 6.90$ (m, 3H, $\mathrm{H}_{\text {arom }}$ ), 5.78 (m, 3H, $\left.3 \times \mathrm{NH}\right), 4.70(\mathrm{~m}, 3 \mathrm{H}, 3 \times \mathrm{CHN}$ ), 3.80 (s, 9H, $3 \times \mathrm{OMe}$ ), 3.5-3.0 (m, $\left.18 \mathrm{H}, 9 \times \mathrm{CH}_{2}\right), 1.46$ (s, 27H, $3 \times \mathrm{CMe}_{3}$ ). Anal. calcd. for $\mathrm{C}_{42} \mathrm{H}_{63} \mathrm{~N}_{3} \mathrm{O}_{21} \mathrm{~S}_{3}$ (1042.15): C, 48.40; H, 6.09; N, 4.03\%. Found: C, 48.37; H, 6.11; N, 4.01\%.

Thermolysis of sulfoxides 3a-d in neat methyl acrylate. General procedure. A 0.1 M solution of $\mathbf{3}$ in methyl acrylate was maintained under stirring at RT until full consumption of the starting sulfoxide (TLC control). The reaction crude was purified by flash column chromatography on silica gel (EtOAc / petroleum ether from 1:9 to 1:1).

\section{Acknowledgements}

The Authors thank the Università degli Studi di Messina for financial support (PRA).

\section{References}

1. (a) Machiguchi, T.; Hasegawa, T.; Otani, H.; Yamabe, S.; Mizuno, H. J. Am. Chem. Soc. 1994, 116, 407. (b) Goto, K.; Tokitoh, N.; Okazaki, R. Angew. Chem., Int. Ed. Eng. 1995, 34, 1124. (c) Ishii, A.; Komiya, K.; Nakayama, J. J. Am. Chem. Soc. 1996, 118, 12836.

2. Aversa, M. C.; Barattucci, A.; Bonaccorsi, P.; Giannetto, P. Curr. Org. Chem. 2007, 11, 1034.

3. Adams, H.; Anderson, J. C.; Bell, R.; Jones, D. N.; Peel, M. R.; Tomkinson, N. C. O. J. Chem. Soc., Perkin Trans. 1 1998, 3967.

4. (a) Aversa, M. C.; Barattucci, A.; Bonaccorsi, P.; Giannetto, P.; Jones, D. N. J. Org. Chem. 1997, 62, 4376. (b) Aversa, M. C.; Barattucci, A.; Bonaccorsi, P.; Giannetto, P.; Nicolo', F. J. Org. Chem. 1999, 64, 2114.

5. For recent reviews about the utilization of the chiral sulfinyl group in asymmetric synthesis, see: (a) Carreño, M. C. Chem. Rev. 1995, 95, 1717. (b) Aversa, M. C.; Barattucci, A.; Bonaccorsi, P.; Giannetto, P. Tetrahedron: Asymmetry 1997, 8, 1339. (c) García Ruano, J. 
L.; Cid de la Plata, B. Top. Curr. Chem. 1999, 204, 1. (d) Fernández, I.; Khiar, N. Chem. Rev. 2003, 103, 3651. (e) Hanquet, G.; Colobert, F.; Lanners, S.; Solladié, G. ARKIVOC (Gainesville, FL, U. S.) 2003, (vii), 328.

6. (a) Aucagne, V.; Aversa, M. C.; Barattucci, A.; Bonaccorsi, P.; Giannetto, P.; Rollin, P.; Tatibouët, A. J. Org. Chem. 2002, 67, 6925. (b) Aversa, M. C.; Barattucci, A.; Bonaccorsi, P.; Giannetto, P. J. Org. Chem. 2005, 70, 1986. (c) Aversa, M. C.; Barattucci, A.; Bilardo, M. C.; Bonaccorsi, P.; Giannetto, P.; Rollin, P.; Tatibouët, A. J. Org. Chem. 2005, 70, 7389. (d) Aversa, M. C.; Barattucci, A.; Bonaccorsi, P.; Faggi, C.; Papalia, T. J. Org. Chem. 2007, 72, 4486.

7. Braverman, S. In The chemistry of sulphenic acids and their derivatives; Patai S. Ed.; John Wiley \& Sons: Chichester, 1990; pp 311-359.

8. (a) De Lucchi, O.; Pasquato, L.; Modena, G. Tetrahedron Lett. 1984, 25, 3643. (b) De Lucchi, O.; Pasquato, L.; Rollin, P.; Tatibouët, A. @-EROS Encyclopedia of Reagents for Organic Synthesis, Copyright 2007 John Wiley \& Sons Ltd.

9. Cavrini, V.; Gotti, R.; Andrisano, V.; Gatti, R. Chromatographia 1996, 42, 515.

10. (a) Kaydos, J. A.; Smith, D. L. J. Org. Chem. 1983, 48, 1096. (b) Benítez, A.; Herrera, F. R.; Romero, M.; Talamás, F. X.; Muchowski, J. M. J. Org. Chem. 1996, 61, 1487. (c) Brown, G. A.; Martel, S. R.; Wisedale, R.; Charmant, J. P. H.; Hales, N. J.; Fishwick, C. W. G.; Gallagher, T. J. Chem. Soc., Perkin Trans. 1 2001, 1281.

11. (a) Ohta, H.; Kato, Y.; Tsuchihashi, G. Chem. Lett. 1986, 217. (b) Burgess, K.; Henderson, I.; Ho, K. K. J. Org. Chem. 1992, 57,1290.

12. (a) Furukawa, N.; Morishita, T.; Akasaka, T.; Oae, S. J. Chem. Soc., Perkin Trans. 2 1980, 432. (b) Allenmark, S.; Nielsen, L.; Pirkle, W. H. Acta Chem. Scand. 1983, B37, 325. (c) Holland, H. L.; Brown, F. M.; Lakshmaiah, G.; Larsen, B. G.; Patel, M. Tetrahedron: Asymmetry 1997, 8, 683. (d) Andersson, M. A.; Allenmark, S. G. Tetrahedron 1998, 54, 15293. (e) Lowendahl, A. C.; Allenmark, S. G. Biocatal. Biotransform. 1998, 16, 163.

13. Hogg, D. R. In The chemistry of sulphenic acids and their derivatives; Patai S. Ed.; John Wiley \& Sons: Chichester, 1990; pp 361-402.

14. Grainger, R. S.; Tisselli, P.; Steed, J. W. Org. Biomol. Chem. 2004, 2, 151.

15. Kim, J. H.; Park, E.-S.; Shim, J. H.; Kim, M.-N.; Moon, W.-S.; Chumg, K.-H.; Yoon, J.-S. J. Agric. Food Chem. 2004, 52, 7480.

16. Cottman, K. S.; Rollick, K. L. 1994, US 5310811 patent, Chem. Abstr. 1995, 122, 11939.

17. (a) Dronov, V. I.; Nigmatullina, R. F.; Zaev, E. E.; Nikitin, Yu. E. Zh. Org. Khim. 1979, 15, 1706, Chem. Abstr. 1980, 92, 6188. (b) Benedetti, F.; Fabrissin, S.; Risaliti, A. J. Chem. Res. (S) 1987,50 . 